
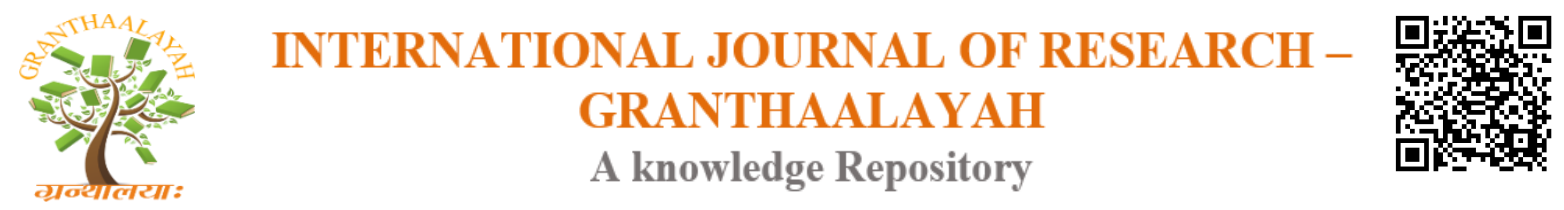

Science

\title{
SPACE RESECTION WITH ZENITH ANGLES
}

\author{
Bektas,S. ${ }^{1}$, Pakel,E. ${ }^{1}$, Yıldırm,R. ${ }^{1}$, Uyar,A. ${ }^{1}$, Yıldırım,Ü,K. ${ }^{1}$, Karaahmetoğlu,N. ${ }^{~}{ }^{1}$ \\ ${ }^{1}$ Geomatics Engineering, Faculty of Engineering, Ondokuz Mayis University, Samsun, 55139, \\ Turkey
}

\begin{abstract}
The problem of determining the position continues to be the most important problem of geodesy. With the development of measuring instruments and techniques, the widespread use of electronic distance meters, the precise and rapid computation possibilities provided by artificial ground satellites and computers, the segmented approach in the positioning problem (separate calculation of horizontal and vertical coordinates) has left the place as an integrated approach, dimensional coordinates have begun to be calculated together. It is possible to determine the $3 \mathrm{D}$ coordinates of the station point with only 3 zenith (vertical) angles. The problem of position determination is done either in the form of basic homework or (usually) predictions. It is also possible to calculate the three-dimensional coordinates of the points by the proposed resection method.
\end{abstract}

Keywords: Space Resection; Three Dimensional Positioning; Zenith (Vertical) Angles; LSQ Method.

Cite This Article: Bektas,S., Pakel,E., Y1ldırm,R., Uyar,A., Y1ldırım,Ü,K., and Karaahmetoğlu,N.. (2018). "SPACE RESECTION WITH ZENITH ANGLES." International Journal of Research - Granthaalayah, 6(2), 331-338. https://doi.org/10.5281/zenodo.1194758.

\section{Introduction}

The problem of geodesic positioning problem was resolved separately as horizontal positioning and vertical positioning.

However, due to the widespread use of electronic distance meters, artificial ground satellites, and accurate and fast computation possibilities provided by computers, the piecewise approach of locating (leaving horizontal and vertical coordinates separately) has left the place as an integrated approach and the three-dimensional coordinates of the points have begun to be calculated together.

Proposed method is iterative based. There are a few studies on closed solutions in the literature [17],[18],[19]. However, the formulas proposed as closed solutions are very long and complicated and are considered to provide no practical benefit. 


\subsection{Three Point Resection in 2D with Distances $(y, x)$}

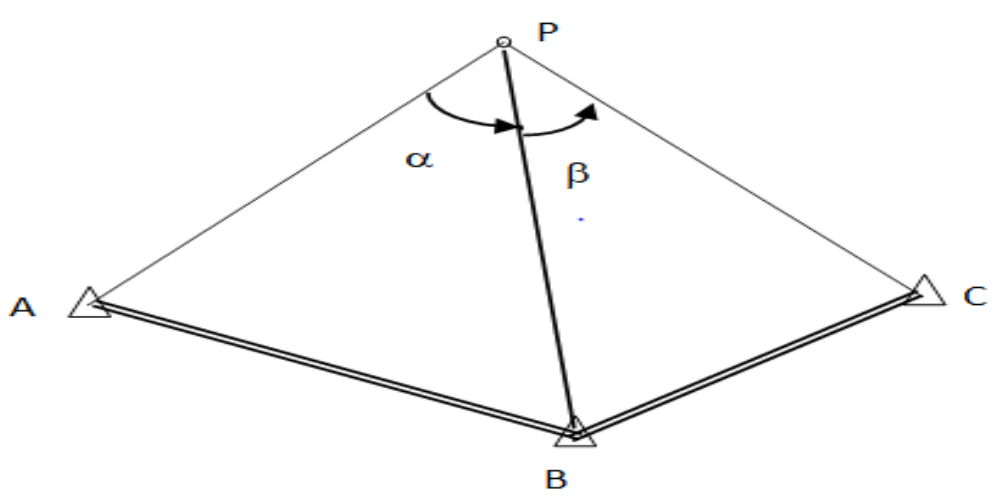

Figure 1: Three point resection in the plane [6]

The three-point resection problem in surveying involves occupying an unknown point and observing angles only to three known points. Today, with the advent of total stations/EDMs, the problem is greatly simplified. If the unknown point $\mathrm{P}$ lies on a circle defined by the three known control points then the solution is indeterminate or not uniquely possible. There are, theoretically, an infinite number of solutions for the observed angles. This situation is called dangerous circle. If the geometry is close to this, then the solution is weak. In addition, there is no solution to this problem when all the points lie on a straight or nearly straight line. There are a number of approaches to solving the resection problem. The coordinates of points $\mathrm{A}, \mathrm{B}$, and $\mathrm{C}$ are known and the angles $\alpha$ and $\beta$ measured at point P. [17], [6]

Kaestner-Burkhardt Method, in the Kaestner-Burkhardt approach [7], [8], [10], [16] the coordinates of points $\mathrm{A}, \mathrm{B}$, and $\mathrm{C}$ are known and the angles $\alpha$ and $\beta$ measured at point P. Collins Method, The Collins (or Bessel's) method [7], [8], [10], [16] is different in that the problem is broken down into two intersections. Cassinı Method, The Cassini approach [7], [10], [16] to the solution of the three-point resection problem is a geometric approach. Tienstra Method, The Tienstra method [3] is also referred to as the Barycentric method. An easy to understand proof is given in [1].

Among these methods, resection methods provide a great measure in the field compared to others. The rewind method is advantageous compared to other shortcut methods, since it is only necessary to make measurements at the point to be estimated. It is easier to make the reestimation with the horizontal direction measure than with the re-estimation with the length measure. Because, in order to measure the lengths and lengths, one person must go to at least three points and keep the reflector (reflector). It is possible to calculate the coordinates of the point $\mathrm{P}$ with three horizontal orientations (two angles) to be made to three points whose coordinates are known only via a $\mathrm{P}$ point for which the calculation of the coordinates is desired. In other shortcut methods there is a necessity to measure at least two points. There is no solution if the dangerous circle dropping point, which is to be estimated in the method of rewinding with the correct measure, i.e. the point to be cut and the other three fixed points are located on the same circle. Theoretically, it is very unlikely to happen in practice. We look at measuring information and geodetic calculus books for reworking accounts and methods. 


\subsection{Three-Dimensional Positioning $(y, x, z)$}

It is possible to calculate the three-dimensional local orthogonal coordinates of the points by the resection method. It is possible to solve this problem by taking advantage of the measured zenith angles. In this case, the problem is also referred to as space resection.

In this method, the three-dimensional coordinates are to be calculated between point $\mathrm{P}$ and at least three points such as $\mathrm{A}\left(y_{a}, x_{a}, z_{a}\right), \mathrm{B}\left(y_{b}, x_{b}, z_{b}\right)$ ve $\mathrm{C}\left(y_{c}, x_{c}, z_{c}\right)$ the $3 \mathrm{D}$ coordinates of the $\mathrm{P}$ $\left(y_{p}, x_{p}, z_{p}\right)$ point can be calculated by the $\alpha, \beta, \gamma$ zenith angles measure [5]. The problem is to find the cutting points of the three cones with peak angle $2 \alpha$ at point A, peak angle $2 \beta$ at point B and peak angle $2 \gamma$ at point $\mathrm{C}$.

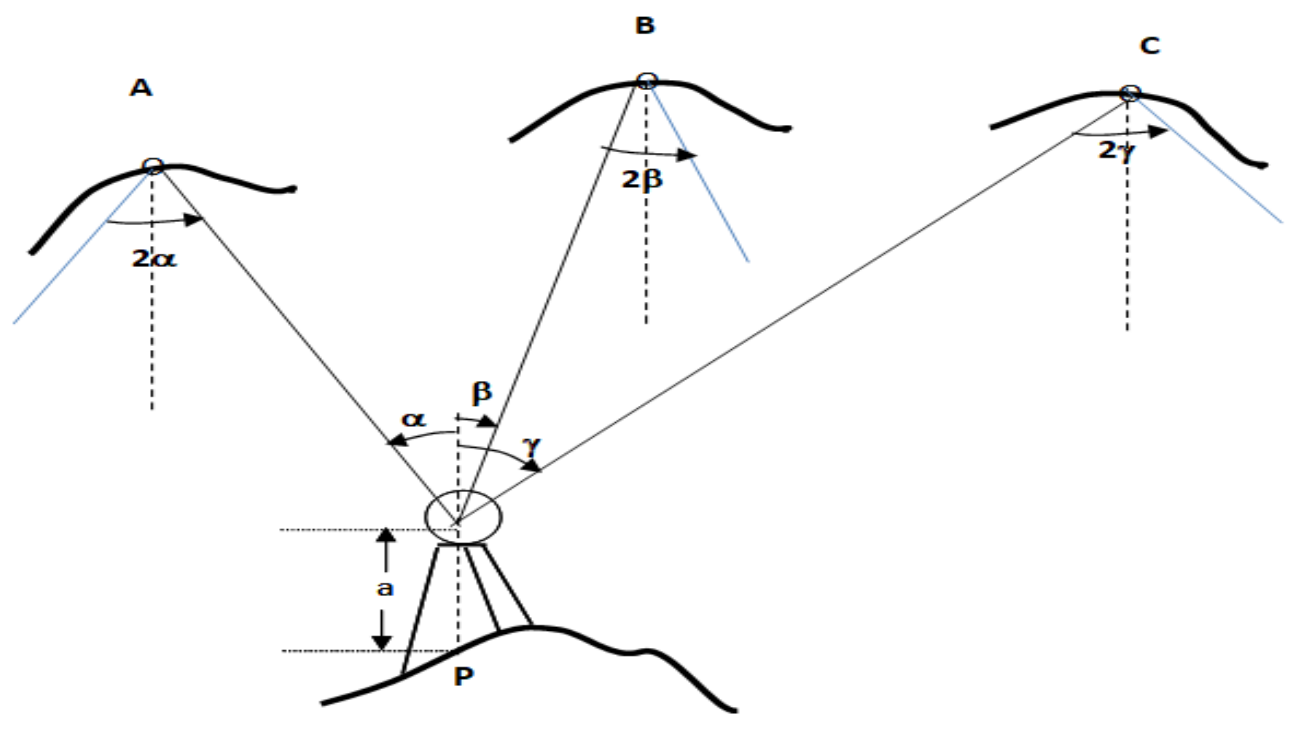

Figure 2: Intersection of three cone [5]

It is important to select approximate coordinates. If the approximate coordinates are not determined in proper proximity, the iterative solution yields the possibility of non-convergence. For the solution of the problem, an equation is written for each measured zenith angle

$$
\begin{aligned}
& \cot \alpha=\Delta z_{a} / s_{a} \\
& \cot \beta=\Delta z_{b} / s_{b} \\
& \cot \gamma=\Delta z_{c} / s_{c}
\end{aligned}
$$

Where

$$
\Delta z_{i}=z_{i}-z_{p} \quad s_{i}=\sqrt{\left(x_{i}-x_{p}\right)^{2}+\left(y_{i}-y_{p}\right)^{2}} \quad(i=a, b, c)
$$

The following linear equation system is obtained if the approximate values for the unknowns are selected and the linearization is performed. The three unknowns of these three equations cannot 
be solved easily because the equations are not linear. For this, the approximate values $y_{o}, x_{o}, z_{o}$ of the unknowns (coordinates of the point P) are selected.

$$
y_{p}=y_{o}+\Delta_{y} \quad x_{p}=x_{o}+\Delta_{x} \quad z_{\mathrm{p}}=z_{o}+\Delta_{z}
$$

And the equations are opened to the Taylor series and if the linearization is done only by the first degree terms, the following linear equation system is obtained. The selection of the approximate values of the coordinates of the point to be estimated can be read out on a large scale map or can be determined roughly from the coordinates of other fixed points. Where $\mathrm{x}, \mathrm{y}, \mathrm{z}$ denote $\mathrm{x}, \mathrm{y}$ the horizontal position and $\mathrm{z}$ coordinates is the vertical position.

If long edges are concerned, the measured vertical angles must be free from spherical and refraction effects. The $\beta$ reduced vertical angle from the measured vertical angle $\beta$ ' is calculated as follows.

$$
\beta=\beta^{\prime}-d \frac{1-k}{2 R} \rho \sin \beta^{\prime}
$$

Where

$k$ : refraction coefficient

$R$ : Radius of Earth

$$
d_{i}=\sqrt{\left(x_{i}-x_{p}\right)^{2}+\left(y_{i}-y_{p}\right)^{2}+\left(z_{i}-z_{p}\right)^{2}}
$$

The system of linearized equations

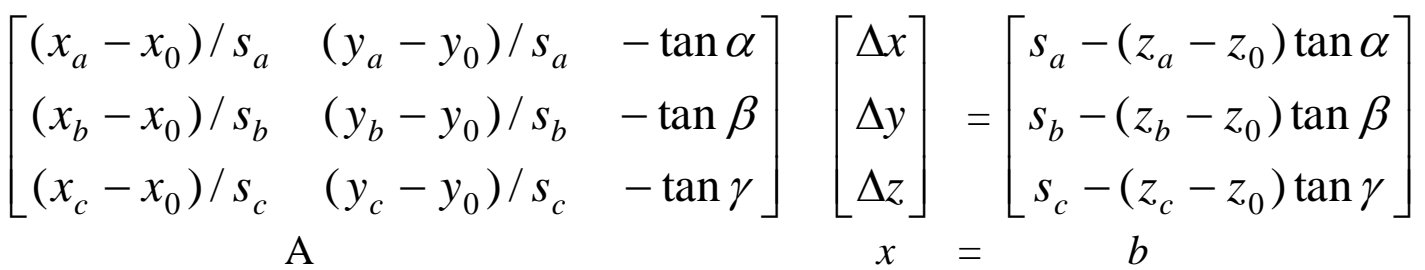

Can be written

$\mathrm{Ax}=b$

Solution of this linear equation system by any method

$x=A^{-1} b$

or MATLAB command

$$
x=\operatorname{inv}(A)^{*} b \quad \text { or } \quad x=A \backslash b
$$

$\Delta \mathrm{x}, \Delta \mathrm{y}, \Delta \mathrm{z}$ unknowns are added and added to the initially selected approximate values 
$x_{p}=x_{o}+\Delta_{x} \quad y_{p}=y_{o}+\Delta_{y} \quad z_{\mathrm{p}}=z_{o}+\Delta_{z}$

The coordinates of the desired P point are found. When the linearization process is performed, the selected approximate values are not as close to real values as they are, and the exact result cannot be reached because of the influence of the second and higher order terms ignored. For this, the values found in the first step

$x_{o}=x_{p} \quad y_{o}=y_{p} \quad z_{o}=z_{p}$

the equation is re-established and solved. If necessary, iteration is done and $\left(y_{p}, x_{p}, z_{p}\right)$ coordinates of the desired $\mathrm{P}$ point's coordinates are found.

But here the $z_{p}$ calculated value of the point $\mathrm{P}$ will be the height of the optical axis of the theodolite at point $\mathrm{P}$. The height of the instruments (a) must be subtracted from the $z_{p}$ calculated value for the true $z_{p}$.

It is also possible to carry out the space resection with the measured slope lengths. But to do the space resection with the zenith angles much easier. Because there is no need to go to the target point in order to measure the vertical angle, but for the length measure it is necessary to go to the target point and hold the reflector.

Three zenith angles measures are sufficient to allow the algebraic solution to be performed without space resection. More than three measures can be used to further increase the accuracy, as well as slope length measurements. In this case, since the number of equations is greater than the number of equations in the linear equations established as $A x=b$ as above, the system of equations according to Least Squares Principle;

$$
A^{T} A x=A^{T} b
$$

Is converted and

$x=\left(A^{T} A\right)^{-1} A^{T} b$

$\Delta \mathrm{x}, \Delta \mathrm{y}$ and $\Delta \mathrm{z}$ are found in a balanced way. But here the $z_{p}$ calculated value of the point $\mathrm{P}$ will be the height of the optical axis of the theodolite at point $\mathrm{P}$. The height of the instrument (a) must be subtracted from the $z_{p}$ calculated value for the true $z_{p}$.

\subsection{Difficulties in Practice}

Here is a theoretically inaccessible solution to space resection by vertical angles. If one of the measured vertical angles is $100 \mathrm{grad}$, the solution cannot be done. However, the possibility of encountering such situations in practice is extremely small. Moreover, the fact that the measured vertical angles are close to the horizon makes the solution obscure, slippery. In order to avoid this situation, it is preferable to select fixed points with a large height difference. 
Especially in the case of algebraic solutions where only 3 vertical angles measures are encountered, $A$ matrix may has bad conditions. In such problems, iterative solutions cannot converge and the result cannot be reached. We recommend using the MATLAB pinv command to take advantage of the pseudo inverse. Instead of equation (6) use below equation

$$
x=\operatorname{pinv}(A, 0.02) * b
$$

The use of more than vertical angles measurements and the selection of fixed points homogeneously distributed on the horizon will eliminate this problem altogether.

\section{Numerical Application}

Calculation of the three-dimensional coordinates of point 500 using the following coordinates of points 100, 101 and 102 and the zenith angles measurements.

Table 1: Fixed points coordinate

\begin{tabular}{|cccc|}
\hline Point & Y & $\mathbf{X}$ & $\mathbf{Z}$ \\
\hline 100 & 371.180 & 437.180 & 140.410 \\
\hline 101 & 325.140 & 212.380 & 140.360 \\
\hline 102 & 116.470 & 348.960 & 140.850 \\
\hline
\end{tabular}

Table 2: Approximate values for unknown point

\begin{tabular}{|cccc|}
\hline Point & $\mathbf{Y}$ & $\mathbf{X}$ & $\mathbf{Z}$ \\
\hline 500 & 227.000 & 340.000 & 209.000 \\
\hline
\end{tabular}

Table 3: Zenith angles (reduced)

\begin{tabular}{|lccl|}
\hline $\boldsymbol{i}$ & from & to & Zenith angles \\
\hline 1 & 500 & 100 & $124.5741^{\mathrm{g}}$ \\
\hline 2 & 500 & 101 & 126.2840 \\
\hline 3 & 500 & 102 & 135.3358 \\
\hline
\end{tabular}

The system of linearized equations as Eq.(4)

$0.559 \Delta x+0.829 \Delta y+2.461 \Delta z=5.097$

$-0.793 \Delta x+0.610 \Delta y+2.283 \Delta z=4.296$

$0.081 \Delta x-0.997 \Delta y+1.613 \Delta z=0.988$

Solution of this linear equation system by any method

Table 4: Iteratively calculated coordinates of unknown point 500

\begin{tabular}{|c|c|c|c|c|c|c|c|}
\hline & $X=X_{0}+\Delta x$ & $\Delta \mathbf{x}$ & $Y=Y_{0}+\Delta y$ & $\Delta \mathbf{y}$ & $\mathbf{Z}=\mathbf{Z}_{\mathbf{0}}+\Delta \mathbf{Z}$ & \multicolumn{2}{|c|}{$\Delta \mathbf{z}$} \\
\hline İteration & (m) & (m) & $(\mathbf{m})$ & $(\mathbf{m}$ & (m) & & (m) \\
\hline 1 & 340.1478 & 0.1478 & 228.5006 & & & 323 & 1.5323 \\
\hline 2 & 340.1448 & -0.0030 & 228.5015 & 0.0010 & 210.5333 & & \\
\hline 3 & 340.1448 & 0.0000 & 228.5015 & -0.0000 & 210.5333 & & \\
\hline
\end{tabular}

Point-500 coordinates after 3 iteration founded 


\section{0 \begin{tabular}{crrr} 
Point & X & Y & Z \\
\cline { 2 - 4 } & 340.1448 & 228.5015 & 210.5333
\end{tabular}}

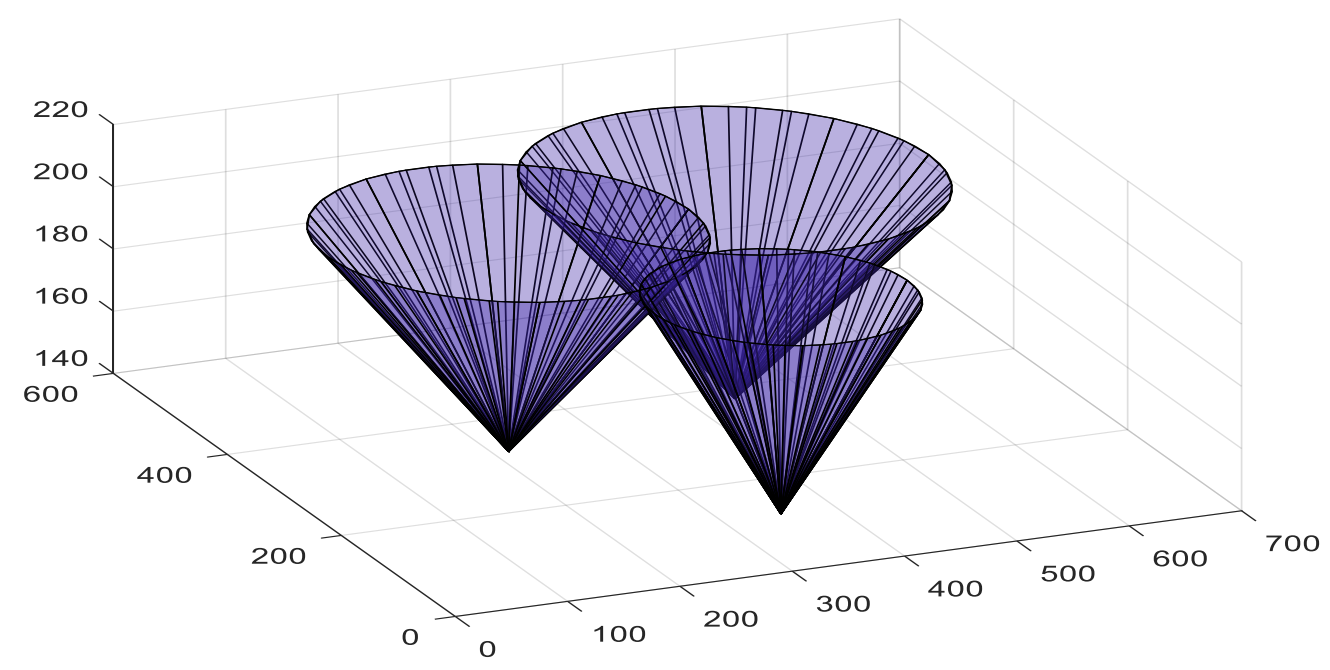

Figure 3: Demonstration of intersection of three cones

\section{Conclusion}

It is possible to calculate the three-dimensional coordinates of the land points with only three vertical angles. Points such as minaret, flag pole, TV, radio transmitter antennas, lightning rod and tower which are known to have high visibility on the ground can be used easily for this work. It is not appropriate to expect high accuracy from the method. Method; can be used as such in engineering works (mining measurements, geological, geophysical, navigation, forestry etc.) that do not require high accuracy. The advantage of the method is that it can only determine the three-dimensional position by taking advantage of the three vertical angles. Higher accuracy is possible with quality measurements and more than 3 measurements [4]. For this; Horizontal and vertical angles, the measurement of length and height leveling measurements must be included in problems.

\section{References}

[1] Allan, A., Hollwey, J., and Maynes, J., 1968. Practical Field Surveying and Computations, American Elsevier Publishing Co., Inc., New York.

[2] Anderson, J. and Mikhail, E., 1998. Surveying: Theory and Practice, 7th edtion, WCB/McGrawHill, New York.

[3] Bannister, A., Raymond, S., and Baker, R., 1984. Surveying, 6th edition, Longman Scientific \& Technical, Essex, England.

[4] Bektaş, S (1992).”Nirengi Ağlarının Üçboyutlu Dengelenmesi ", Türkiye III. Harita ve Teknikerlik Hizmetleri Kurultayı ", 13-16 Nisan 1992 Ankara

[5] Bektaş,S. (1997). Uzay Geriden Kestirme, Harita ve Kadastro Mühendisliği Dergisi, say1 : 83 , s.72-79, Ekim 1997, Ankara

[6] Bektaş,S. (2016). Pratik Jeodezi, II.Baskı, OMÜ yayınları, Samsun

[7] Blachut, T., Chrzanowski, A., and Saastamoinen, J., 1979. Urban Surveying and Mapping, Springer-Vrlag, New York. 
[8] Faig, W., 1972. "Advanced Surveying I (Preliminary Copy), Department of Surveying Engineering Lecture Notes No. 26, University of New Brunswick, Fredericton, N.B., Canada, 225 p.

[9] Hodgson, C., 1957. Manual of Second and Third Order Triangulation and Traverse, USC\&GS Special Publication No. 145 (Reprinted, 1957), U.S. Government Printing Office, Washington, D.C.

[10] Kissam, P., 1981. Surveying for Civil Engineers, 2nd edition, McGraw-Hill, New York.

[11] Klinkenberg, H., 1955. "Coordinate Systems and the Three Point Problem", The Canadian Surveyor, XII(8):508-518. SURE 215 -

[12] Surveying Calculations Three Point Resection Problem Page 201 Reynolds, W., 1934.

[13] Manual of Triangulation Computation and Adjustment, USC\&GS Special Publication No. 138 (Reprinted, 1955), U.S. Government Printing Office, Washington, D.C.

[14] Öztürk. E. - Şerbetçi. M.(1989): "Dengeleme Hesabı Cilt II", KTÜ yayınları, yayın no:144,sayfa :310, Trabzon

[15] Şerbetçi, M. -Atasoy, V(1990) :"Jeodezik Hesap", KTÜ yayınları, yayın no: 153, Trabzon

[16] Ziemann, H., 1974. "Terrestrial Surveying Methods", Proceedings of ACSM Fall Convention, Washington, D.C., September, pp 222-233.

[17] Zeng,Z, Wang,X. 1992, A General Solution of a Closed-Form Space Resection, PHOTOGRAMMETRIC ENGINEERING \& REMOTE SENSING, Vol. 58, No.3, March 1992, pp 327-338.

[18] Rampal, K.1979, Closed Solution for Space Resection, PHOTOGRAMMETRIC ENGINEERING AND REMOTE SENSING, Vol. 45, No. 9, September 1979, pp. 1255-1261.

[19] Awange,J.L, Grafarend/Fukuda 2003, Closed form solution of the triple three-dimensional intersection problem, geodaesie.info/.../zfv_2003_6_

[20] URL-1: Three Point Resection Problem, Surveying Engineering Department Ferris State University, Accessed date .27.01.2017

[21] URL-2: http://oarnorthwest.com/wp-content/uploads/2013/02/gps3.jpg, Accessed date: 27.01.2018

*Corresponding author.

E-mail address: nihatkara28@ gmail.com 